\title{
Finite Element Analysis and Test of Braze Residual Stress Between Different Materials
}

\author{
Liu Shichao*, Pang Xueman, Zhou Hao, Cheng Kai \\ Nanjing Electronic Devices Institute, Nanjing, China \\ Email address: \\ 18652075567@163.com (Liu Shichao) \\ ${ }^{*}$ Corresponding author
}

To cite this article:

Liu Shichao, Pang Xueman, Zhou Hao, Cheng Kai. Finite Element Analysis and Test of Braze Residual Stress Between Different Materials. Journal of Electrical and Electronic Engineering. Vol. 7, No. 3, 2019, pp. 75-81. doi: 10.11648/j.jeee.20190703.11

Received: May 21, 2019; Accepted: July 2, 2019; Published: July 12, 2019

\begin{abstract}
To assess the rationality and reliability of the finite element model, finite element analysis and test were performed on the braze residual stress between two materials with different expansion coefficients. The samples used in this paper were obtained by welding tungsten - copper wafers and kovar wafers. The finite element analysis method and stress testing method are introduced briefly. In order to describe the welding process, this paper uses several related equations to illustrate the simulation calculation, and introduces the complex analysis process of the test method, and briefly introduces the processing method of the test data. The test results mainly include the residual stress values corresponding to different depths on the drilling path, and the stress state at this position is expressed by tensile stress and compressive stress. The results of finite element simulation analysis are comprehensive. In order to compare with the test results, the direction and size of tensile stress and compressive stress of the section are selected. The results of test are consistent with those of finite element analysis. It was suggested that the residual stress obtained from the finite element model is feasible and can be referenced to understand the residual stress of the actual devices. Then an example is given to verify the consistency of the two methods.
\end{abstract}

Keywords: Finite Element, Stress, Braze

\section{The Introduction}

Residual stresses will be inevitable in the interior of the object after the materials with different thermal expansion coefficients are welded together. The magnitude of these residual stresses in the shell affects the reliability of the encapsulated device. If the residual stress inside the shell is too large, deformation, cracking and air leakage of the encapsulated device will be caused, seriously affecting the reliability of the device and even lead to device failure. To effectively assess the reliability of the shell, Many experts at home and abroad have done pioneering research. Morgan first proposed the calculation example of thermal stress and thermal strain in multilayer electronic package in 1991. The use of metal-solder-metal three-layer structure, considering the influence of solder, proved the feasibility of finite element (FEM) in package stress calculation [1]. Now various types of finite element analysis software were used to predict the residual stress of the shell after fiber welding, which is recently a common method for shell reliability assessment
[2-5]. However, the theoretical residual stress of the shell is obtained using this method. The stress is required to be tested quantitatively to verify the rationality of the finite element simulation model.

The methods for measurement of residual stress mainly are mechanical release method and non-destructive method [6]. In this study, the blind hole method as a mechanical release method was adopted to test the residual stress of the brazed sample using the stress tester, and the stress generated in the soldering process of the sample was analyzed using the finite element analysis software ABAQUS. By comparing the test results with the simulation results, the rationality of the finite element model was verified.

\section{Sample Structure}

The samples were welded together with silver-copper solder using materials with different thermal expansion coefficients. The shrinkage of different materials during solder solidification is inconsistent, leading to the formation of 
residual stress zone at the interface of heterogeneous materials. The structure and size of the sample are shown in Figure 1, composed of rounded flake 1 and rounded flake 2 and solder. Rounded flake 1 of the sample is kovar (4J29), rounded flake 2 is tungsten copper (WCu15), and the solder is $\mathrm{AgCu} 28$.

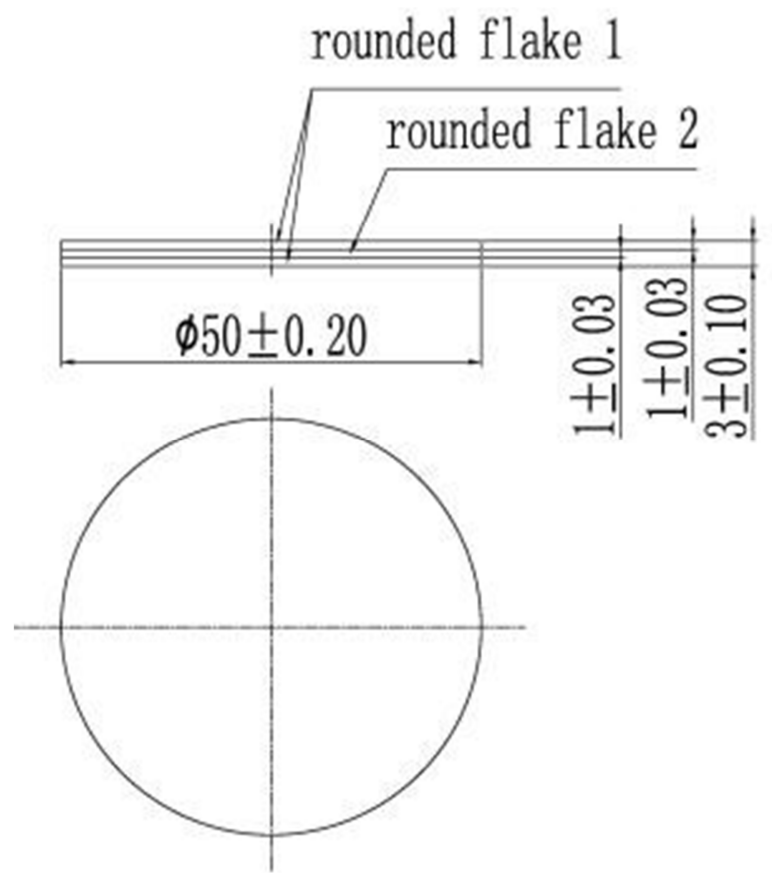

Figure 1. Structure and sizes of the sample.

\section{Finite Element Analysis}

\subsection{Calculation}

The residual stress of sample after brazing was analyzed using finite element method. To improve the calculation, it was assumed that the plasticizing point of solder is in the "zero stress state" during brazing, and the temperature difference between temperature and room temperature is taken as the temperature load. Besides, thermal radiation was assumed as the only heat conduction way in the process of rising and cooling. The whole sample geometry model was taken as the solution region, and the stress value obtained acted as the residual stress [7], Secondly, the material deformation in the whole brazing process was assumed as an ideal linear elastic deformation without plastic deformation. The physical parameters of the material are listed in Table 1.
Table 1. Physical capability of material.

\begin{tabular}{lll}
\hline Material & W85Cu & 4J29 \\
\hline Coefficient of Thermal Expansion $\left(\mathrm{ppm} /{ }^{\circ} \mathrm{C}\right)$ & 6.7 & 7.85 \\
Elasticity $(\mathrm{GPa})$ & 117 & 170 \\
Poison's Ratio & 0.27 & 0.27 \\
Conductivity $[\mathrm{W} /(\mathrm{m} \cdot \mathrm{k})]$ & 180 & 16.4 \\
Specific heat $[\mathrm{J} /(\mathrm{kg} \cdot \mathrm{K})]$ & 134 & 460 \\
Density $\left(\mathrm{kg} / \mathrm{m}^{3}\right)$ & 17740 & 8170 \\
\hline
\end{tabular}

Since the solder parts are thin, the stress distribution has small impacts on other parts, so the solder was ignored when modeling [8, 9]. Moreover, the welding interface was assumed to be closely connected to the ideal surface. In the process of soldering, the temperature of "zero stress state" was $810^{\circ} \mathrm{C}$. The temperature of the residual stress of the simulation was $25^{\circ} \mathrm{C}$.

\subsection{Computational Process}

After the binding of different materials, the state of the object was calculated by the equilibrium equation of temperature displacement, the thermal radiation equation, the heat expansion equation, and the boundary equation [10]. The meaning of parameters in the formula is shown in Table 2.

Table 2. The meaning of parameters in the formula.

\begin{tabular}{ll}
\hline parameter & meaning \\
\hline$\tau$ & $\begin{array}{l}\text { Conjugate pairing of material stress } \\
\text { Virtual quantities are infinitesimally small variations of } \\
\text { physical measures, such as displacement, strain, velocity, } \\
\text { and so on. }\end{array}$ \\
$\varepsilon$ & Conjugate pairing of material strain \\
$\mathrm{t}$ & The surface traction vector \\
$\mathrm{v}$ & The velocity field vector \\
$\mathrm{f}$ & The body force vector \\
$\rho$ & The current mass density \\
$\mathrm{U}$ & The internal energy per unit mass \\
$\theta$ & temperature \\
$\mathrm{k}$ & The thermal conductivity matrix \\
$\mathrm{r}$ & The heat generated within the body \\
$\mathrm{q}$ & The heat flux per unit area of the body, flowing into the \\
$\mathrm{F}$ & body \\
$\sigma$ & The geometrical viewfactor matrix \\
$\eta$ & The Stefan-Boltzmann constant \\
$\alpha$ & emissivity \\
$\varphi$ & Coefficient of Thermal Expansion \\
$\mathrm{N}$ & The finite rotation vector \\
$\mathrm{u}$ & A set of N vector interpolation functions \\
$\mathrm{g}$ & displacement \\
\hline
\end{tabular}

$$
\left\{\begin{array}{c}
\int_{\mathrm{V}_{0}} \tau^{\mathrm{c}}: \delta \varepsilon \mathrm{dV}^{0}=\int_{\mathrm{S}} \mathrm{t}^{\mathrm{T}} \cdot \delta \mathrm{vdS}+\int_{\mathrm{V}} \mathrm{f}^{\mathrm{T}} \cdot \delta \mathrm{vdV} \\
\int_{\mathrm{V}} \rho \dot{\mathrm{U}} \delta \theta \mathrm{dV}+\int_{\mathrm{V}} \frac{\partial \delta \theta}{\partial \mathrm{x}} \cdot \mathrm{k} \cdot \frac{\partial \theta}{\partial \mathrm{x}} \mathrm{dV}=\int_{\mathrm{V}} \delta \theta \mathrm{rdV}+\int_{\mathrm{S}_{\mathrm{p}}} \delta \theta \mathrm{qdS}+\int_{\mathrm{S}_{\mathrm{i}}} \delta \theta \mathrm{q}_{\mathrm{r}} \mathrm{dS} \\
\mathrm{q}_{\mathrm{r}}=\frac{\mathrm{F} \sigma}{\frac{1}{\eta_{\mathrm{A}}+\frac{1}{\eta}-1}}\left[\left(\theta_{\mathrm{A}}-\theta^{\mathrm{Z}}\right)^{4}-\left(\theta-\theta^{\mathrm{Z}}\right)^{4}\right] \\
\varepsilon^{\mathrm{th}}=\alpha\left(\theta, \mathrm{f}_{\beta}\right)\left(\theta-\theta^{0}\right)-\alpha\left(\theta^{\mathrm{I}}, \mathrm{f}_{\beta}^{\mathrm{I}}\right)\left(\theta^{\mathrm{I}}-\theta^{0}\right) \\
\delta \mathrm{x}^{\mathrm{s}}=\delta \mathrm{x}^{\mathrm{m}}+\delta \Phi^{\mathrm{m}} \times\left(\mathrm{x}^{\mathrm{s}}-\mathrm{x}^{\mathrm{m}}\right)+\delta \mathrm{y}_{\mathrm{i}} \mathrm{e}_{\mathrm{i}}
\end{array}\right.
$$




$$
\begin{aligned}
& \left\{\begin{array}{c}
\mathrm{I}_{\mathrm{u}}^{\mathrm{M}}=\int_{\mathrm{V}_{0}} \beta^{\mathrm{M}}: \tau^{\mathrm{c}} \mathrm{dV}^{0}-\int_{\mathrm{S}} \mathrm{N}_{\mathrm{M}}^{\mathrm{T}} \cdot \mathrm{tdS}-\int_{\mathrm{V}} \mathrm{N}_{\mathrm{M}}^{\mathrm{T}} \cdot \mathrm{fdV}=0 \\
\mathrm{I}_{\theta}^{\mathrm{P}}=\frac{\frac{1}{\Delta \mathrm{t}} \int_{\mathrm{V}} \mathrm{N}_{\mathrm{P}} \rho\left(\mathrm{U}_{\mathrm{t}+\Delta \mathrm{t}}-\mathrm{U}_{\mathrm{t}}\right) \mathrm{dV}+\int_{\mathrm{V}} \frac{\partial \mathrm{N}_{\mathrm{P}}}{\partial \mathrm{x}} \cdot \mathrm{k} \cdot \frac{\partial \theta}{\partial \mathrm{x}} \mathrm{dV}}{-\int_{\mathrm{V}} \mathrm{N}_{\mathrm{P}} \mathrm{rdV}-\int_{S_{\mathrm{p}}} \mathrm{N}_{\mathrm{P}} \mathrm{qdS}-\int_{S_{\mathrm{i}}} \mathrm{N}_{\mathrm{P}} \mathrm{q}_{\mathrm{r}} \mathrm{dS}}=0
\end{array}\right.
\end{aligned}
$$

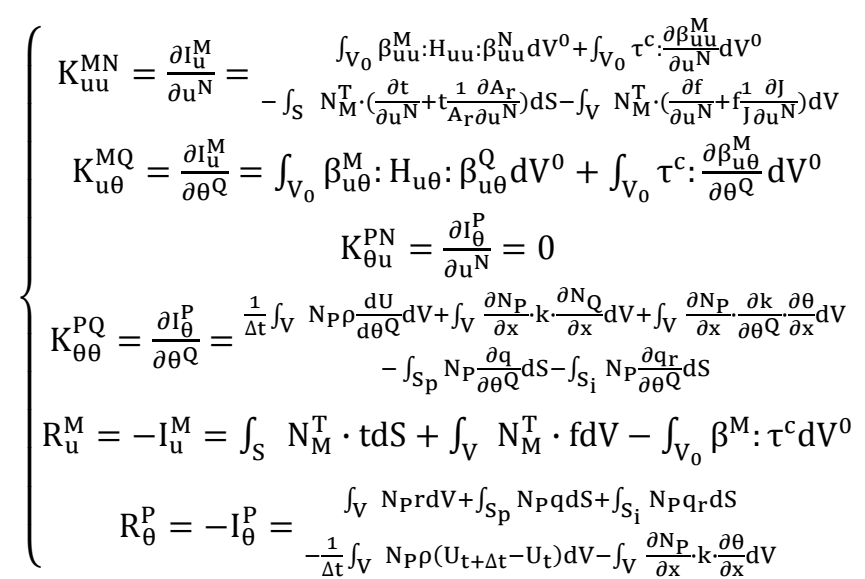

$$
\begin{gathered}
{\left[\begin{array}{cc}
\mathrm{K}_{\mathrm{uu}, \mathrm{i}}^{\mathrm{MN}} & \mathrm{K}_{\mathrm{u} \theta, \mathrm{i}}^{\mathrm{MQ}} \\
\mathrm{K}_{\theta \mathrm{u}, \mathrm{i}}^{\mathrm{PN}} & \mathrm{K}_{\theta \theta, \mathrm{i}}^{\mathrm{PQ}}
\end{array}\right]\left\{\begin{array}{l}
\Delta \mathrm{u}_{\mathrm{i}+1} \\
\Delta \theta_{\mathrm{i}+1}
\end{array}\right\}=\left\{\begin{array}{l}
\mathrm{R}_{\mathrm{u}, \mathrm{i}}^{\mathrm{M}} \\
\mathrm{R}_{\theta, \mathrm{i}}^{\mathrm{P}}
\end{array}\right\}} \\
\mathrm{u}_{\mathrm{t}, \mathrm{i}+1}=\mathrm{u}_{\mathrm{t}, \mathrm{i}}+\Delta \mathrm{u}_{\mathrm{t}, \mathrm{i}+1} \\
\theta_{\mathrm{t}, \mathrm{i}+1}=\theta_{\mathrm{t}, \mathrm{i}}+\Delta \theta_{\mathrm{t}, \mathrm{i}+1} \\
\mathrm{~g}_{\mathrm{t}, \mathrm{i}+1}=\mathrm{f}_{\mathrm{g}}\left(\mathrm{u}_{\mathrm{t}, \mathrm{i}+1}, \theta_{\mathrm{t}, \mathrm{i}+1}\right)
\end{gathered}
$$

When $\left|\Delta \mathrm{u}_{\mathrm{t}, \mathrm{i}+1}\right|<\varepsilon$ and $\left|\Delta \theta_{\mathrm{t}, \mathrm{i}+1}\right|<\mu$,

$$
\begin{gathered}
\mathrm{g}_{\mathrm{t}} \approx \mathrm{g}_{\mathrm{t}, \mathrm{i}+1} \\
\mathrm{u}_{\mathrm{t}+\Delta \mathrm{t}, 0}=\mathrm{f}_{\mathrm{u}}\left(\mathrm{u}_{\mathrm{t}, \mathrm{i}+1}, \Delta \mathrm{t}\right) \\
\theta_{\mathrm{t}+\Delta \mathrm{t}, 0}=\mathrm{f}_{\theta}\left(\theta_{\mathrm{t}, \mathrm{i}+1}, \Delta \mathrm{t}\right)
\end{gathered}
$$

\subsection{Analysis of Simulation}

According to the simulation results of the finite element model, the simulated stress values corresponding to different depths in the borehole path during the sample test, as shown in Figure 2, could be obtained.

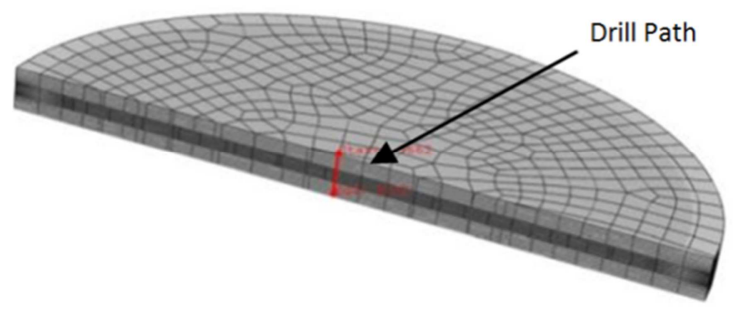

Figure 2. Indication of drill path in stress simulation.

Figure 3 shows the simulated values of tensile stress corresponding to different depths on the drilling path of the sample, and Figure 4 shows the simulated values of compressive stress.

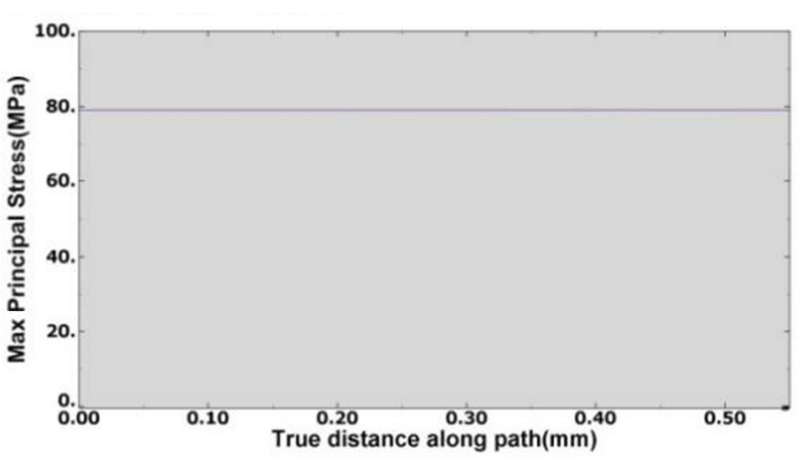

Figure 3. Simulated Max Principal stress on drill path.

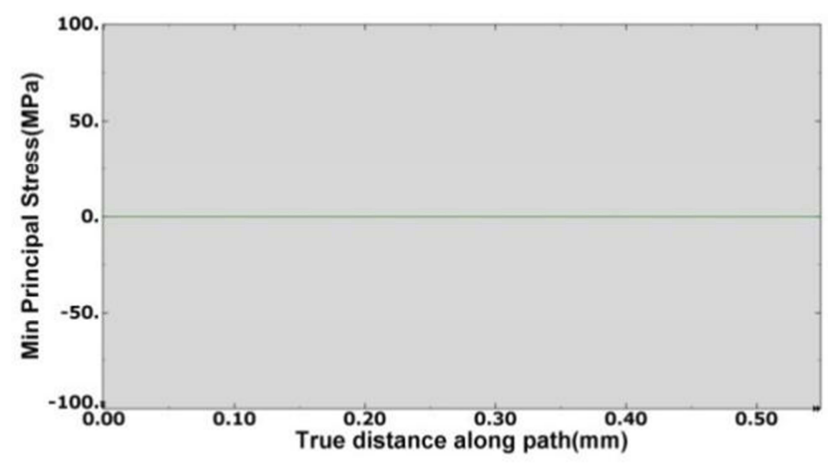

Figure 4. Simulated Min Principal stress on drill path.

\section{Stress Test}

\subsection{Test Method}

Pinhole method is a mature and reliable method to measure residual stress, which has hign precision, low damage to structure and easy operation [11]. In the test sample (as shown in Figure 1) on the surface, strain gages were used, and borehole strain gauge position was made correspond to the circle of the sample. Subsequently, the leads on the strain gauge data gathering line were welded together, the rig 
location was adjusted, blind hole was drilled in the size of $\Phi 2.0 \mathrm{~mm} \times 1.5 \mathrm{~mm}$, and the stress testing platform was used to collect and record the strain release a quantity to the drilling path.

\subsection{Basic Principles}

The basic principal of the blind hole method for measuring residual stress is that in an isotropic material with residual stress, the residual stress field in a local area will be uniform. After drilling a small hole, the continuity of the material was destroyed, and the radial stress at the hole edge dropped to zero, causing the redistribution of the stress field near the hole area $[12,13]$. In this study, the static strain measurement method was adopted, the strain value was measured by the strain gauge combined with the strain gauge tester, and then the residual stress was calculated in accordance with the elastic mechanics theory. Usually, the surface residual stress is a state of plane stress, containing two principal stresses and one principal direction Angle, i.e. three unknowns, as shown in Figure 5. The analysis of plane stress state with complex numbers is presented as follows $[14,15]$ :

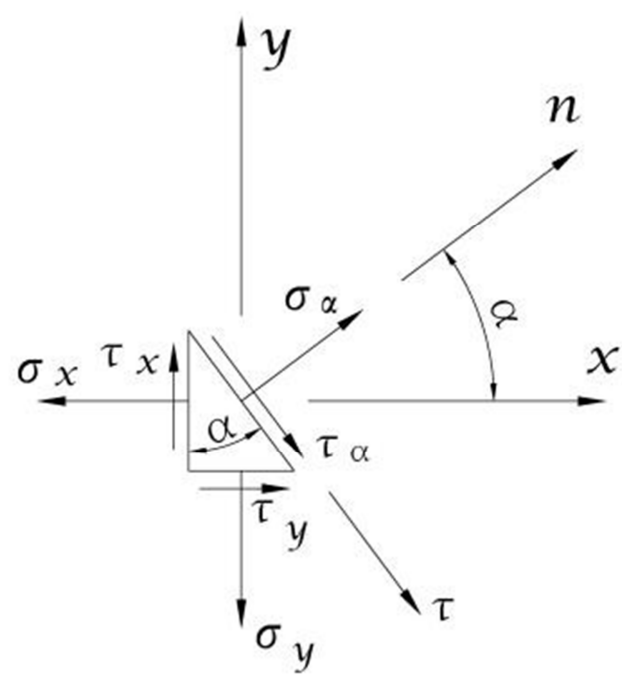

Figure 5. Instruction of stress.

$$
\begin{gathered}
\left\{\begin{array}{c}
\sum \mathrm{F}_{\mathrm{n}}=\begin{array}{c}
\sigma_{\alpha} \mathrm{dA}+\left(\tau_{\mathrm{x}} \mathrm{dA} \cos \alpha\right) \sin \alpha-\left(\sigma_{\mathrm{x}} \mathrm{dA} \cos \alpha\right) \cos \alpha \\
+\left(\tau_{\mathrm{y}} \mathrm{dA} \sin \alpha\right) \cos \alpha-\left(\sigma_{\mathrm{y}} \mathrm{dA} \sin \alpha\right) \sin \alpha
\end{array}=0 \\
\sum \mathrm{F}_{\tau}=\begin{array}{c}
\tau_{\alpha} \mathrm{dA}-\left(\tau_{\mathrm{x}} \mathrm{dA} \cos \alpha\right) \cos \alpha-\left(\sigma_{\mathrm{x}} \mathrm{dA} \cos \alpha\right) \sin \alpha \\
+\left(\tau_{\mathrm{y}} \mathrm{dA} \sin \alpha\right) \sin \alpha+\left(\sigma_{\mathrm{y}} \mathrm{dA} \sin \alpha\right) \cos \alpha
\end{array}=0
\end{array}\right. \\
\left\{\begin{array}{c}
\sigma_{\alpha}=\frac{\sigma_{\mathrm{x}}+\sigma_{\mathrm{y}}}{2}+\frac{\sigma_{\mathrm{x}}-\sigma_{\mathrm{y}}}{2} \cos 2 \alpha-\tau_{\mathrm{x}} \sin 2 \alpha \\
\tau_{\alpha}=\frac{\sigma_{\mathrm{x}}-\sigma_{\mathrm{y}}}{2} \sin 2 \alpha+\tau_{\mathrm{x}} \cos 2 \alpha
\end{array}\right. \\
\left\{\begin{array}{c}
\varepsilon_{\mathrm{x}}=\frac{1}{\mathrm{E}}\left[\sigma_{\mathrm{x}}-\mathrm{v} \sigma_{\mathrm{y}}\right] \\
\varepsilon_{\mathrm{y}}=\frac{1}{\mathrm{E}}\left[\sigma_{\mathrm{y}}-\mathrm{v} \sigma_{\mathrm{x}}\right] \\
\gamma_{\mathrm{xy}}=\frac{\tau_{\mathrm{x}}}{\mathrm{G}} \\
\mathrm{G}=\frac{\mathrm{E}}{2(1+\mathrm{v})}
\end{array}\right.
\end{gathered}
$$

$$
\left\{\begin{array}{c}
\varepsilon_{\alpha}=\frac{\varepsilon_{\mathrm{x}}+\varepsilon_{\mathrm{y}}}{2}+\frac{\varepsilon_{\mathrm{x}}-\varepsilon_{\mathrm{y}}}{2} \cos 2 \alpha-\frac{\gamma_{\mathrm{xy}}}{2} \sin 2 \alpha \\
\frac{\gamma_{\alpha}}{2}=\frac{\varepsilon_{\mathrm{x}}-\varepsilon_{\mathrm{y}}}{2} \sin 2 \alpha+\frac{\gamma_{\mathrm{xy}}}{2} \cos 2 \alpha
\end{array}\right.
$$

Let $\mathrm{z}_{\mathrm{x}}=\varepsilon_{\mathrm{x}}+\mathrm{j} \frac{\gamma_{\mathrm{xy}}}{2}, \mathrm{z}_{\mathrm{c}}=\frac{\varepsilon_{\mathrm{x}}+\varepsilon_{\mathrm{y}}}{2}, \mathrm{z}_{\mathrm{y}}=\varepsilon_{\mathrm{y}}-\mathrm{j} \frac{\gamma_{\mathrm{xy}}}{2}, \mathrm{z}_{\alpha}=\varepsilon_{\alpha}+\mathrm{j} \frac{\gamma_{\alpha}}{2}$,

$$
\mathrm{z}_{\alpha}-\mathrm{z}_{\mathrm{c}}=\left(\mathrm{z}_{\mathrm{x}}-\mathrm{z}_{\mathrm{c}}\right) \mathrm{e}^{\mathrm{j} 2 \alpha}
$$

Assuming $\mathrm{z}_{\mathrm{x}}-\mathrm{z}_{\mathrm{c}}=\mathrm{re}^{\mathrm{j} 2 \alpha_{0}}$,

$$
\mathrm{z}_{\alpha}-\mathrm{z}_{\mathrm{c}}=r \mathrm{re}^{\mathrm{j}\left(2 \alpha_{0}+2 \alpha\right)}
$$

Let $z_{0}=\varepsilon_{0}+j \frac{\gamma_{0}}{2}, z_{\frac{\pi}{4}}=\varepsilon \frac{\pi}{4}+j \frac{\gamma \frac{\pi}{4}}{2}, z_{\frac{\pi}{2}}=\varepsilon_{\frac{\pi}{2}}+j \frac{\gamma \frac{\pi}{2}}{2}$,

$$
\begin{aligned}
& \left\{\begin{array}{c}
z_{0}-z_{c}=r e^{j 2 \alpha_{0}} \\
z_{\frac{\pi}{4}}-z_{c}=r e^{j\left(2 \alpha_{0}+\frac{\pi}{2}\right)} \\
z_{\frac{\pi}{2}}-z_{c}=r e^{j\left(2 \alpha_{0}+\pi\right)}
\end{array}\right. \\
& \left\{\begin{array}{c}
\mathrm{z}_{\mathrm{c}}=\frac{\varepsilon_{0}+\varepsilon_{\frac{\pi}{2}}}{2} \\
\tan 2 \alpha_{0}=\frac{\varepsilon_{0}+\varepsilon_{\frac{\pi}{2}}-2 \varepsilon_{\frac{\pi}{4}}}{\varepsilon_{0}-\frac{\varepsilon \pi}{2}} \\
r=\frac{\sqrt{\left(\varepsilon_{0}+\varepsilon_{\frac{\pi}{2}}-2 \varepsilon \frac{\pi}{4}\right)^{2}+\left(\varepsilon_{0}-\varepsilon_{\frac{\pi}{2}}\right)^{2}}}{2}
\end{array}\right.
\end{aligned}
$$

When $2 \alpha_{0}+2 \alpha=0$,

$$
\left\{\varepsilon_{\max }=\frac{\varepsilon_{0}+\varepsilon_{\frac{\pi}{2}}}{2}+\frac{\sqrt{\left(\varepsilon_{0}+\frac{\varepsilon \pi}{2}-2 \varepsilon \frac{\pi}{4}\right)^{2}+\left(\varepsilon_{0}-\frac{\varepsilon \pi}{2}\right)^{2}}}{2}\right.
$$

When $2 \alpha_{0}+2 \alpha=\pi$,

$$
\left\{\begin{array}{c}
\varepsilon_{\min }=\frac{\varepsilon_{0}+\varepsilon \frac{\pi}{2}}{2}-\frac{\sqrt{\left(\varepsilon_{0}+\varepsilon \frac{\pi}{2}-2 \varepsilon \frac{\pi}{4}\right)^{2}+\left(\varepsilon_{0}-\frac{\varepsilon \pi}{2}\right)^{2}}}{2} \\
\frac{\gamma_{\frac{\pi}{2}-\alpha_{0}}}{2}=0
\end{array}\right.
$$

When $2 \alpha_{0}+2 \alpha= \pm \frac{\pi}{2}$

$$
\begin{aligned}
& \left\{\begin{array}{c}
\varepsilon_{ \pm \frac{\pi}{4}-\alpha_{0}}=\frac{\varepsilon_{0}+\varepsilon_{\frac{\pi}{2}}}{2} \\
\frac{|\gamma|_{\max }}{2}=\frac{\sqrt{\left(\varepsilon_{0}+\varepsilon_{\frac{\pi}{2}}-2 \varepsilon_{\frac{\pi}{4}}\right)^{2}+\left(\varepsilon_{0}-\varepsilon_{\frac{\pi}{2}}\right)^{2}}}{2}
\end{array}\right. \\
& \left\{\begin{array}{c}
\sigma_{\max }=\frac{\mathrm{E}}{1-\mathrm{v}^{2}}\left[\varepsilon_{\max }+\mathrm{v} \varepsilon_{\min }\right] \\
\sigma_{\min }=\frac{\mathrm{E}}{1-\mathrm{v}^{2}}\left[\varepsilon_{\min }+\mathrm{v} \varepsilon_{\max }\right] \\
|\tau|_{\max }=\mathrm{G}|\gamma|_{\max }
\end{array}\right.
\end{aligned}
$$




$$
\left\{\begin{array}{c}
\sigma_{\max }=\frac{\mathrm{E}}{1-\mathrm{v}} \frac{\varepsilon_{0}+\varepsilon_{\frac{\pi}{2}}}{2}+\frac{\mathrm{E}}{1+\mathrm{v}} \frac{\sqrt{\left(\varepsilon_{0}+\varepsilon_{\frac{\pi}{2}}-2 \varepsilon \frac{\pi}{4}\right)^{2}+\left(\varepsilon_{0}-\varepsilon_{\frac{\pi}{2}}\right)^{2}}}{2} \\
\sigma_{\min }=\frac{\mathrm{E}}{1-\mathrm{v}} \frac{\varepsilon_{0}+\varepsilon_{\frac{\pi}{2}}}{2}-\frac{\mathrm{E}}{1+\mathrm{v}} \frac{\sqrt{\left(\varepsilon_{0}+\varepsilon_{\frac{\pi}{2}}-2 \varepsilon_{\frac{\pi}{4}}\right)^{2}+\left(\varepsilon_{0}-\varepsilon_{\frac{\pi}{2}}\right)^{2}}}{2} \\
|\tau|_{\max }=\frac{\mathrm{E}}{2(1+\mathrm{v})} \sqrt{\left(\varepsilon_{0}+\varepsilon_{\frac{\pi}{2}}-2 \varepsilon_{\frac{\pi}{4}}\right)^{2}+\left(\varepsilon_{0}-\varepsilon_{\frac{\pi}{2}}\right)^{2}}
\end{array}\right.
$$

\subsection{Test Steps}

The experimental equipment for stress testing is shown in Figure 6, and the specific operation steps are as follows:

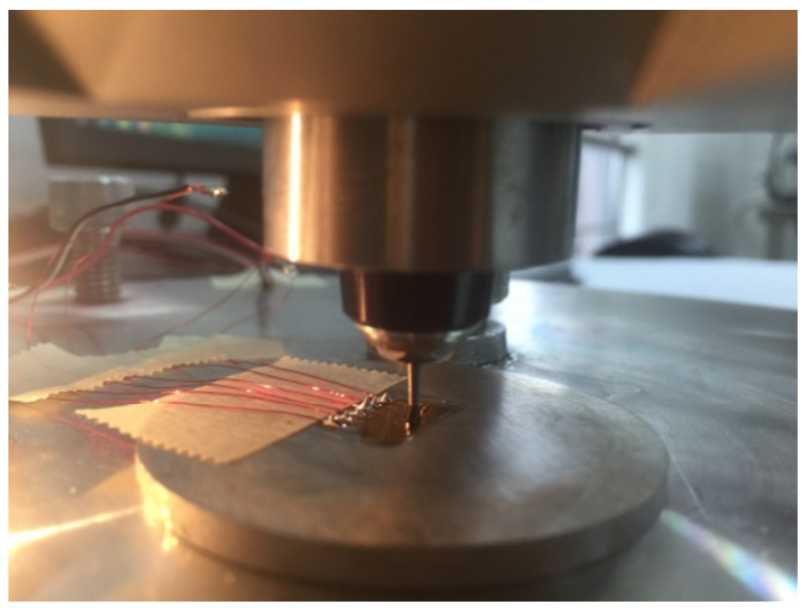

Figure 6. The stress tester.
1. The sample surface was cleaned. Oil stains were removed from the surface of the sample with an oil remover, and then the sample was wiped dry with a gauze. The measuring surface of the sample was grinded with coarse and fine sandpaper, respectively, and the measuring surface was cleaned.

2. Strain gauge was pasted. The strain gauge was tightly stuck on the workpiece to be tested.

3. Welding. The lead wire was welded on the strain gauge to the data acquisition line.

4. Fix the drill floor. The drill bit could be aligned with the stress measuring point by adjusting the relative position of drill floor and strain gauge.

5. System calibration. The data collector and computer software were run, making them in the state of receiving signals; a new test file was created, and strain gauge information was inputted.

6. Drilling. The sample was drilled from the measuring point using a compressed air driven drill. After drilling slowly to a certain depth, when the real-time monitoring value of strain is constant, the corresponding data of the depth will be recorded.

7. Analysis. The actual stress value was obtained by analyzing the recorded data with software.

\subsection{Test Results}

Figure 7 shows the values of tensile stress and compressive stress of the samples obtained from the data acquisition system software StrainSmart.

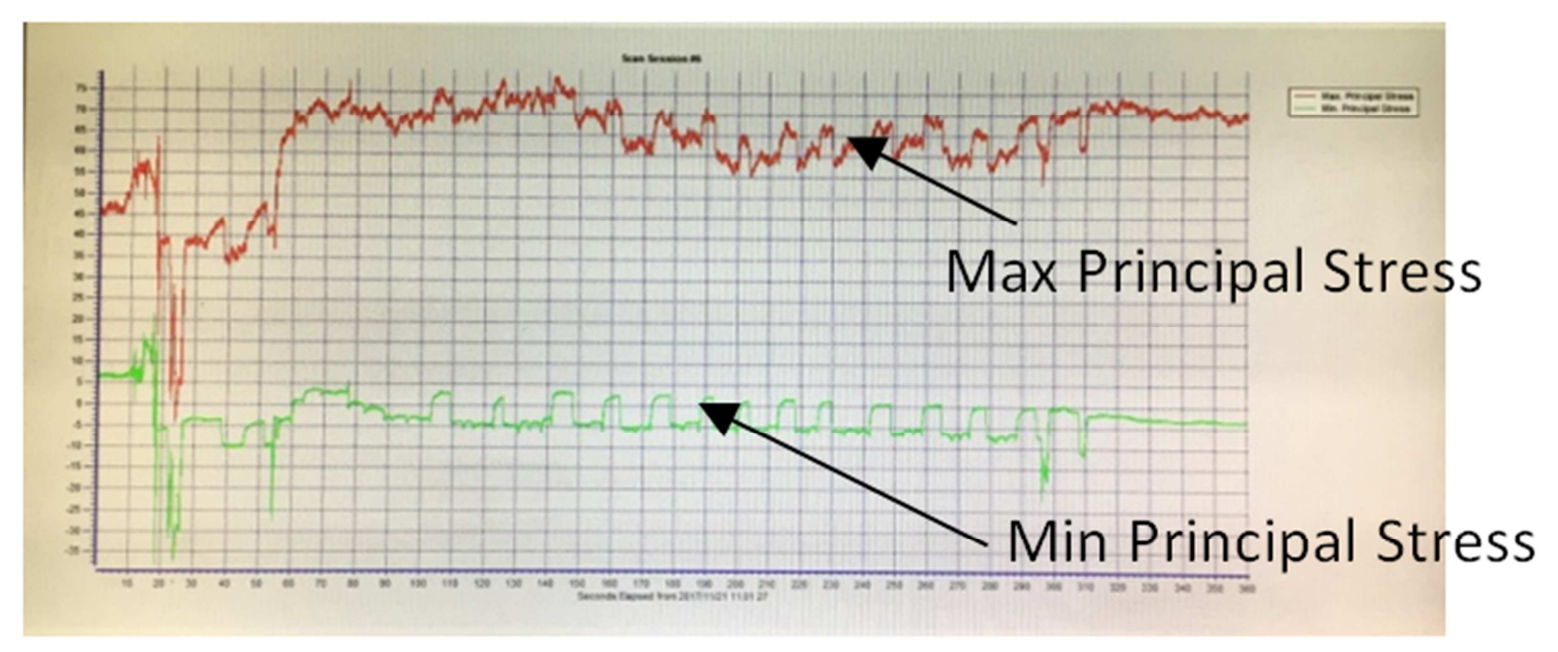

Figure 7. Max Principal stress and Min Principal stress measured by StrainSmart.

\section{Consistency Analysis of Test and Simulation}

The direction of simulated tensile stress on the section where the borehole path of the sample is located is shown in Figure 8. The corresponding StrainSmart tensile stress test value and the simulated tensile stress value of ABAQUS are shown in Figure 9.

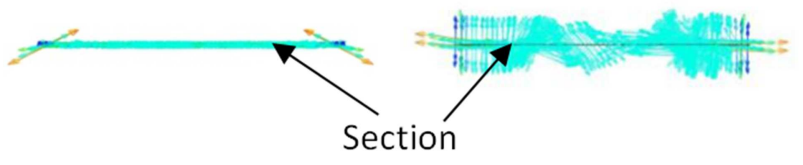

Front view

Top view

Figure 8. Direction of Max Principal stress on the plane of drill path. 


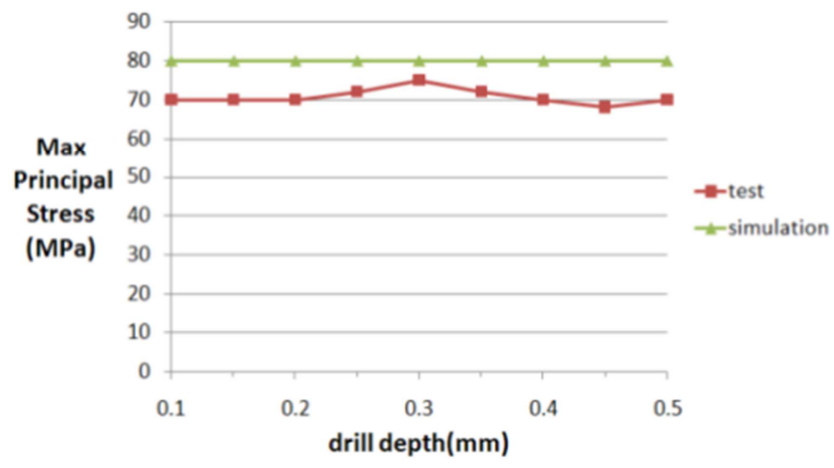

Figure 9. Max Principal stress of test and simulation.

Figure 9 suggests that the tensile stress value of the sample measured by StrainSmart is consistent with corresponding simulation result.

Figure 10 shows the direction of simulated compressive stress on the section where the drilling path of the sample is located, and Figure 11 shows the corresponding SrainSmart compressive stress test value and the ABAQUS tensile stress simulation value.

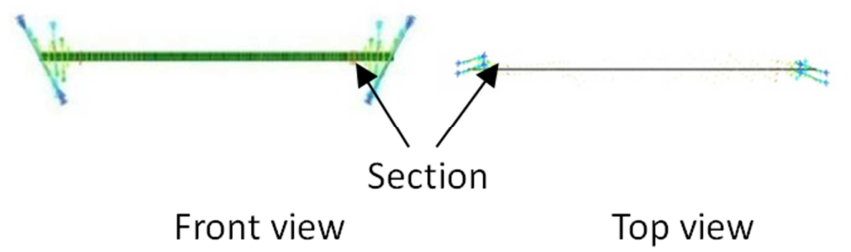

Figure 10. Direction of Min Principal stress on the plane of drill path.

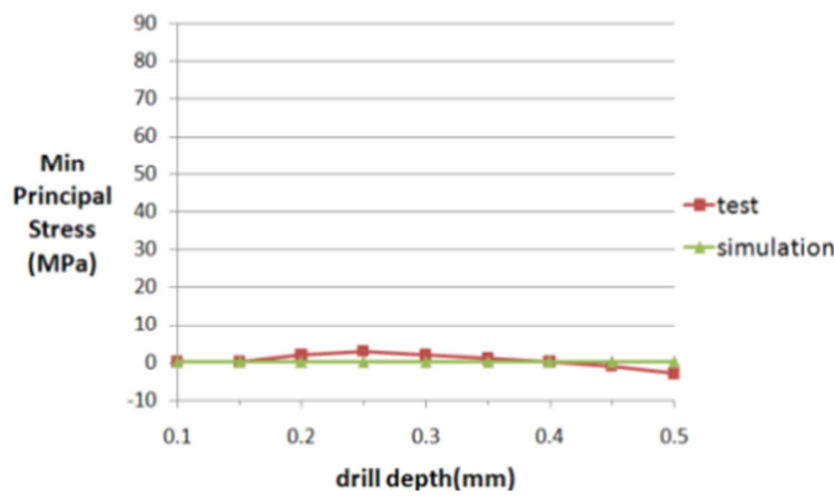

Figure 11. Min Principal stress of test and simulation.

Figure 11 suggests that the compressive stress value of the sample measured by StrainSmart is consistent with the corresponding simulation result.

\section{Test and Simulation of Thermal Sink Residual Stress of Package Shell}

The same method was employed to test the residual stress of a package shell heat sink. The test equipment and test results are shown in Figure 12. The Abaqus software was also used to simulate the thermal stress along the drilling path, and the simulation model and calculation results are shown in Figure 13.
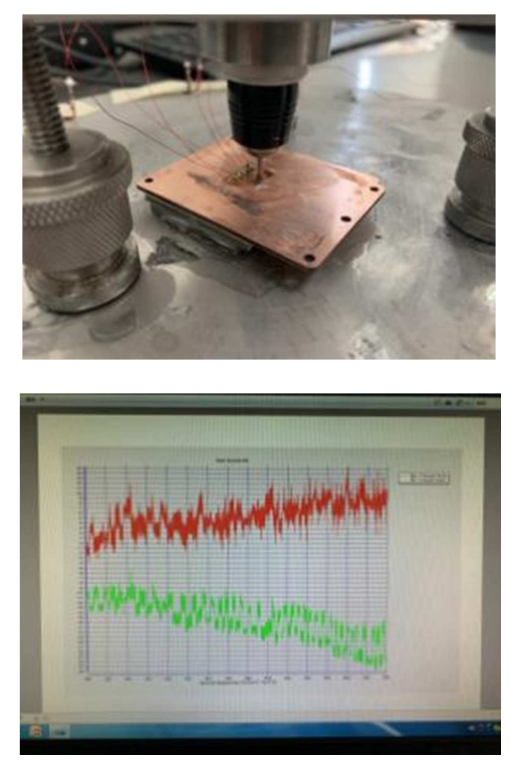

Figure 12. The stress test of heatsink.
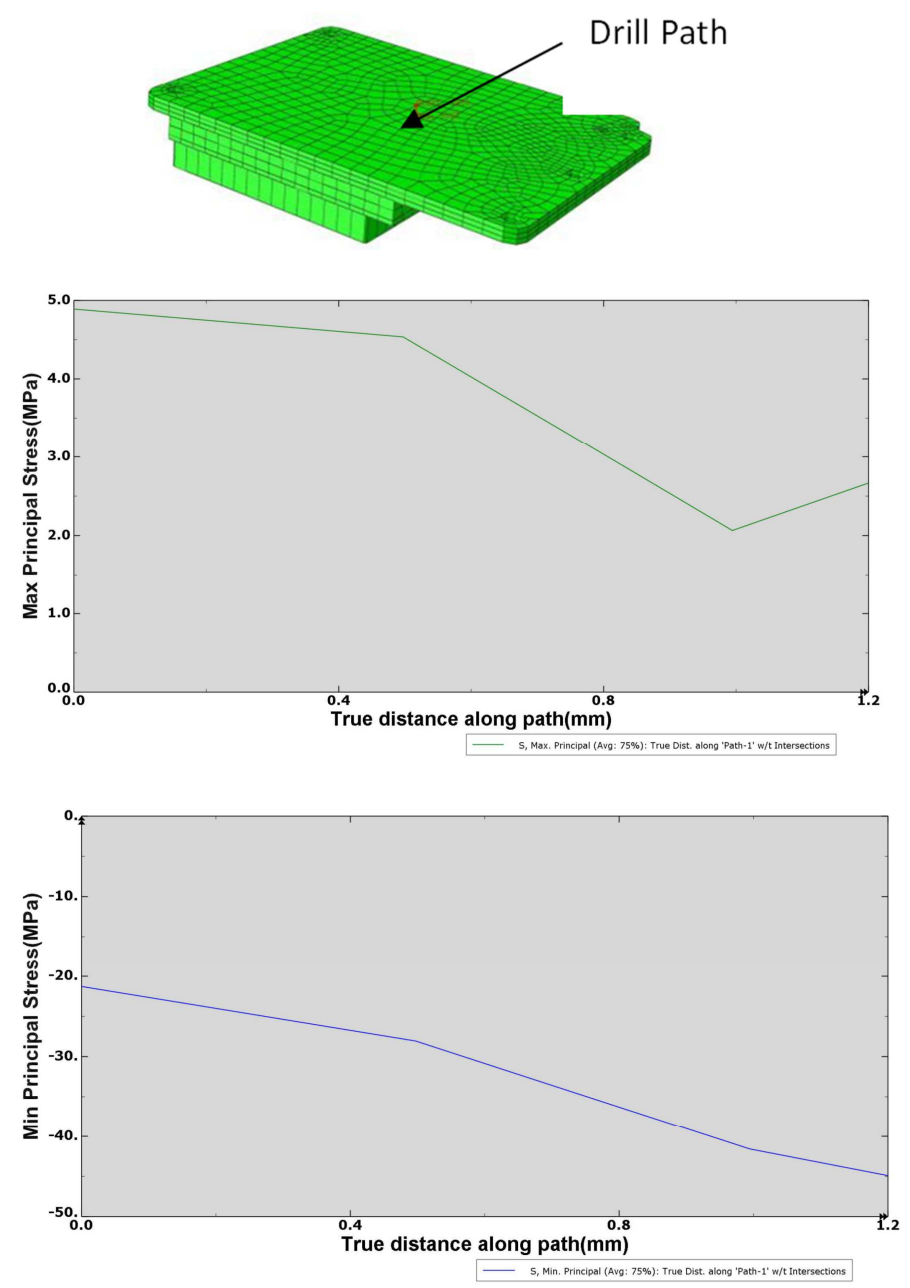

Figure 13. The stress simulation of heatsink.

The direction of simulated tensile stress on the section where the drilling path of heat sink is located is shown in Figure 14, and the direction of simulated compressive stress is shown in Figure 15. The stress test value of 
ABAQUS are shown in Figure 16. Figure 16 suggests that the stress state reflected by the test value and the simulation value are close.

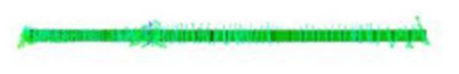

\section{Front view}

Top view

Figure 14. Direction of Max Principal stress on the heatsink section of drill path.
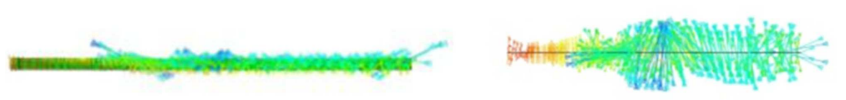

Front view

Top view

Figure 15. Direction of Min Principal stress on the heatsink section of drill path.

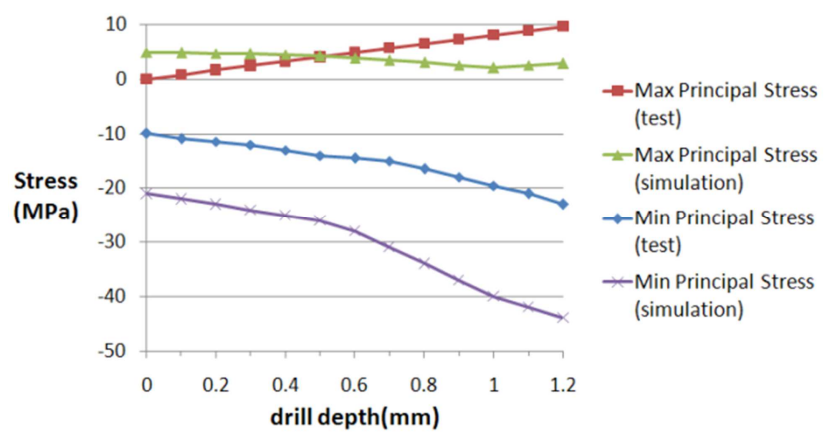

Figure 16. Stress of test and simulation on heatsink.

\section{Conclusion}

To measure the residual stress of the sample, the blind hole method was adopted. According to a comparative analysis of the numerical values of tensile stress and compressive stress obtained from the simulation and test, the simulation results are well consistent with those of the test, verifying the approximation between the finite element model and the actual sample and, to a large extent, reflecting the rationality and reliability of the finite element model. Because material parameters used in the simulation model and the application of the analysis steps have a wide range, the verification test improved the reference value of the finite element model for the analysis of brazing residual stress, thus developing a more effective analysis method for understanding the rationality and reliability of device structure and size design.

As the stress of the test equipment requires the sample to be in a plane state with a large area, it is insufficient to use the equipment for the actual test. However, the residual stress test of some shell heat sink helps to know the stress state and rough stress of the test position in detail.

\section{References}

[1] Morgan H S. Thermal stresses in layered electrical assemblies bonded with solder [J]. ASME Journal of Electronic Packaging. 1991, 113 (4): 350-354.

[2] Wang xuemei, Sun xuewei. Thermal stress analysis of power device shells [J]. Semiconductor science, 2000, 21 (4): 409-413.

[3] Liu xiaojia, Lin jian, lei yongping, etc. Measurement and finite element analysis of residual stress on electron beam welding surface of titanium alloy [J]. Journal of aeronautical materials, 2016, 36 (4): 35-40.

[4] Si jianwen, Guo huaixin, Wang ziliang. TO-type ceramic shell seal failure mode finite element analysis [J]. Electronics \& packing, 2016, 16 (2): 9-13.

[5] KN Tu. Reliability challenges in 3D IC packaging technology [J]. Microelectronics Reliability, 2011 (51): 517-523.

[6] Chen Hui-li, Zhong Yi, Wang Hua-kun, etc. Research progress of the method for residual stress measurement [J]. Yunnan Metallurgy, 2005, 34 (3): 52-54.

[7] Guo huaixin, $\mathrm{Hu}$ jin, Cao kun. Finite element analysis of residual stress in $\mathrm{Al} 2 \mathrm{O} 3$ _WCu package [J]. Research and development of solid state electronics, 2014, 34 (5): 492-497.

[8] Yap Boon Kar, Noor Azrina Talik. Finite element analysis of thermal distributions of solder ball in flip chip ball grid array using ABAQUS [J]. Microelectronics International, 2013, 1 (30): 14-18.

[9] LI Xin-yu, Gao Longqiao, Lu Yan-ping, etc. Finite element stress analysis on nitride aluminum ceramics to Kovar Metal Sealing parts [J], 2009: 75-77.

[10] Abaqus Theory Manual.

[11] Li weilong, Yu li, Wang xuanguo. Test of residual stress by hole drilling strain method $[\mathrm{J}]$. Wuhan Iron and Steel Corporation Technology, 2013, 51 (6): 55-59.

[12] An huping. review of strain method for solving principal stress formula under special plane stress state [J]. Automation\&instrumentation, 2014, 34 (7): 181-184.

[13] Song tianmin. Generation and elimination of welding residual stress [M]. Beijing: China chemistry press, 2004.

[14] Liu dongjia. The study of plane stress states with complex numbers [J]. Mechanics and practice, 1997, 19 (5): 70-72.

[15] Sun xunfang, Fang xiaoshu, Lu yaohong. Mechanics of materials (vol. 2). Beijing: higher education press, 1991, 333 343.

\section{Biography}

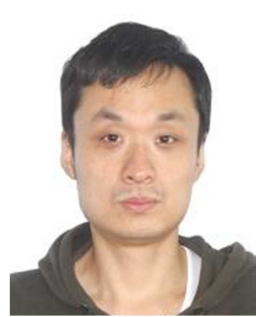

Liu Shichao male, born in 1987, is an engineer with a bachelor's degree. Now he works in the $55^{\text {th }}$ research institute of China electronics science and technology corporation, mainly engaged in electronic packaging design. 